\title{
CAVI vs. pressure and stiffness gradients in the arterial tree
}

Hypertension Research (2010) 33, 380; doi:10.1038/hr.2010.4; published online 5 February 2010

The arterial tree has pressure and stiffness gradients along its longitudinal axis (that is, lower blood pressure and lower stiffness in proximal sites). In disease states (that is, increased arterial stiffness), these gradients are diminished. Recent clinical studies have proposed the significances of increased arterial stiffness and abnormal pressure wave reflection as markers of cardiovascular risk. $^{1,2}$ The plausible underlying mechanisms of this increased cardiovascular risk are increased cardiac afterload, impaired coronary blood flow, atherogenesis and/or endorgan damage. ${ }^{2}$ Abnormal pressure and stiffness gradients are considered to have some causal role in these mechanisms.

Masugata et al. ${ }^{3}$ reported that the central blood pressure (CBP) and cardio-ankle vascular index (CAVI) reflect different facets of cardiovascular pathophysiology. CBP is a reliable marker for understanding the pressure gradient in the arterial tree. On the other hand, CAVI is calculated using the following equation: $\operatorname{In}(\mathrm{Ps} / \mathrm{Pd}) \times 2 p /$ deltaP $\times \mathrm{PWV}^{2}$; ${ }^{4}$ this equation seems to be based on the assumption that the arterial tree is a homogeneous tube (that is, no pressure gradient and no stiffness gradient). Therefore, CBP is a marker of the pathophysiological abnormalities related to arterial stiffness taking into consideration the significance of abnormal pressure and stiffness gradients as cardiovascular risk factors. On the contrary, CAVI may be a marker of the pathophysiological abnormalities related to arterial stiffness without considering the significance of abnormal pressure and stiffness gradients.

As Professor Kohara commented, ventricular-arterial coupling is one of the important issues related to cardiac structural and functional abnormalities. ${ }^{5}$ Therefore, if data on the heart-ankle pulse wave velocity (PWV) are available, we propose an additional analysis to compare the significance of the relationship of the parameters of cardiac structure and function with the CBP and heart-ankle PWV. In contrast to the CAVI, the heart-ankle PWV does not ignore the pressure and stiffness gradients in the arterial tree.

Hirofumi Tomiyama and Akira Yamashina
Second Department of Internal Medicine,
Tokyo Medical University, Tokyo, Japan
E-mail: tomiyama@tokyo-med.ac.jp

1 Zoungas S, Asmar RP. Arterial stiffness and cardiovascular outcome. Clin Exp Pharmacol Physiol 2007; 34: 647-651.

2 Tomiyama $\mathrm{H}$, Yamashina A. Non-invasive vascular function tests. Circ J 2010; 74: 24-33.

3 Masugata H, Senda S, Okuyama H, Murao K, Inukai M, Hosomi N, Yukiiri K, Nishiyama A, Kohno M, Goda F. Comparison of central blood pressure and cardio-ankle vascular index for association with cardiac function in treated hypertensive patients. Hypertens Res 2009; 32: $1136-1142$.

4 Shirai K, Utino J, Otsuka K, Takata M. A novel blood pressure-independent arterial wall stiffness parameter; cardio-ankle vascular index (CAVI). J Atheroscler Thromb 2006; 13: 101-107.

5 Kohara K. Central blood pressure, arterial stiffness and the heart in hypertensive patients. Hypertens Res 2009; 32: 1056-1058. 